\title{
Analysis of Parkinson disease patients from Portugal for mutations in SNCA, PRKN, PINKI and LRRK2
}

Jose Bras'1,3, Rita Guerreiro1,3, Maria Ribeiro 1,2, Ana Morgadinho'2, Cristina Januario ${ }^{2}$, Margarida Dias ${ }^{4}$, Ana Calado ${ }^{4}$, Cristina Semedo ${ }^{4}$, Catarina Oliveira ${ }^{1,2}$, John Hardy ${ }^{3}$ and Andrew Singleton*3

Address: ${ }^{1}$ Center for Neurosciences and Cell Biology, Faculty of Medicine, University of Coimbra, Coimbra, Portugal, ${ }^{2}$ Neurology Service, Coimbra University Hospital, Coimbra, Portugal, ${ }^{3}$ Laboratory of Neurogenetics, National Institutes on Aging, National Institutes of Health, Bethesda, Maryland, USA and ${ }^{4}$ Neurology Service, Lisbon Hospital Center - Center Region EPE, Lisbon, Portugal

Email: Jose Bras - brasj@nia.nih.gov; Rita Guerreiro - portalegrer@nia.nih.gov; Maria Ribeiro - mhgarrucho@huc.min-saude.pt; Ana Morgadinho - anamorgadinho@portugalmail.pt; Cristina Januario - cristinajanuario@gmail.com; Margarida Dias - msilvadias@netcabo.pt; Ana Calado - al_calado@yahoo.com; Cristina Semedo - crissemedo@gmail.com; Catarina Oliveira - catarina@cnc.uc.pt; John Hardy - hardyj@mail.nih.gov; Andrew Singleton* - singleta@mail.nih.gov

* Corresponding author

Published: 22 January 2008

BMC Neurology 2008, 8:1 doi:10.1186/147/-2377-8-1
Received: 12 June 2007

Accepted: 22 January 2008

This article is available from: http://www.biomedcentral.com/147/-2377/8/I

(c) 2008 Bras et al; licensee BioMed Central Ltd.

This is an Open Access article distributed under the terms of the Creative Commons Attribution License (http://creativecommons.org/licenses/by/2.0), which permits unrestricted use, distribution, and reproduction in any medium, provided the original work is properly cited.

\begin{abstract}
Background: Mutations in the genes PRKN and LRRK2 are the most frequent known genetic lesions among Parkinson's disease patients. We have previously reported that in the Portuguese population the LRRK2 c.6055G > A; p.G20I9S mutation has one of the highest frequencies in Europe.
\end{abstract}

Methods: Here, we follow up on those results, screening not only LRRK2, but also PRKN, SNCA and PINKI in a cohort of early-onset and late-onset familial Portuguese Parkinson disease patients. This series comprises 66 patients selected from a consecutive series of 132 patients. This selection was made in order to include only early onset patients (age at onset below 50 years) or late-onset patients with a positive family history (at least one affected relative). All genes were sequenced bidirectionally, and, additionally, SNCA, PRKN and PINKI were subjected to gene dosage analysis.

Results: We found mutations both in LRRK2 and PRKN, while the remaining genes yielded no mutations. Seven of the studied patients showed pathogenic mutations, in homozygosity or compound heterozygosity for PRKN, and heterozygosity for LRRK2.

Conclusion: Mutations are common in Portuguese patients with Parkinson's disease, and these results clearly have implications not only for the genetic diagnosis, but also for the genetic counseling of these patients.

\section{Background}

Parkinson's disease (PD) is clinically characterized by resting tremor, rigidity, bradykinesia, and postural instability [1]. The gold standard of PD diagnosis remains a patho- logical one. Pathological hallmarks include cell loss in pigmented nuclei and the formation of eosinophilic intracytoplasmic inclusions, termed Lewy bodies, particularly in the dopaminergic neurons of the substantia nigra pars 
compacta [2,3]. So far, mutations in SNCA (Alpha-synuclein; OMIM\#163890), PRKN (Parkin OMIM\#602544), DJ1 (Oncogene DJ1 OMIM\#602533), PINK1 (PTENInduced Putative Kinase 1 OMIM\#608309) and LRRK2 (Leucine-Rich Repeat Kinase 2 OMIM\#609007) have been implicated as causes of monogenic PD [4-9].

A missense mutation within SNCA encoding the protein alpha-synuclein was the first identified genetic cause of PD [6] and copy number mutations at this locus have also been shown to cause familial PD [10]. Mutations in PRKN are a common cause of autosomal recessive early-onset parkinsonism [11,7], however mutations in PINK1 and DJ-1 have also been reported as associated with this type of parkinsonism, although only five causative mutations have been described in the latter [12-14]. Mutations in the gene LRRK2 are a common cause of autosomal dominant and apparently sporadic PD. The LRRK2 mutation c.6055G > A; p.G2019S, accounts for 1-2\% of typical sporadic PD in the North American and Northern European white population, with higher prevalence in Portuguese (6\%), Ashkenazi Jewish (18.3\%) and North African Arab populations (39\%) [15-18].

We had previously shown that the c.6055G > A; p.G2019S mutation in LRRK2 is common in Portuguese PD patients [15]. Here we extend upon this study to search for additional LRRK2, SNCA, PRKN and PINK1 mutations in a clinic-based cohort of patients, mainly from the central region of Portugal.

\section{Methods}

After obtaining informed consent, 132 PD patients underwent a standardized neurological examination by a movement disorder specialist. The diagnosis of PD was based on the UK Brain Bank diagnostic criteria (family history was not used as an exclusion criterion) and those published by Gelb et. al. $[2,19]$. Family history was considered positive if parkinsonism was reported in at least a first- or second-degree relative. Collection of these 132 patients was performed at the Movement Disorder Clinics of both the University of Coimbra Hospital and the Lisbon Hospital Center - Center Region EPE in Lisbon, in a consecutive manner, all patients consent to participate. This cohort is identical to that previously described by us except for the inclusion of 4 additional PD patients [15]. From this series of 132 subjects we have selected 66 unrelated patients to include only those with a positive family history for parkinsonism, or early-onset disease (age at onset $<50$ years of age). The remaining 66 patients failed to meet either of these criteria, were related to a proband already included or had previously been found to carry the LRRK2 c.6055G > A; p.G2019S mutation $(\mathrm{n}=11)$. This selection led to the inclusion of 39 patients with positive family history and 46 patients with early-onset PD;
19 patients presented with both an early-onset phenotype and a positive family history, thus the net number of patients from both inclusion groups is 66 (Table 1 ).

Additionally we have included a control group comprised of 126 healthy subjects as previously described [15]. Briefly, this control group consisted primarily of spouses accompanying patients to the clinic $(\sim 80 \%)$; the remaining controls were recruited from non-neurology outpatient clinics, after observation by the movement disorders specialist. This series presented a mean age of $60.5 \pm 23.1$ years. Apart from the spouses of the patients, no other familiarity with movement disorders patients was found. All individuals are Caucasian and of apparent Portuguese ancestry.

Genomic DNA was extracted from peripheral blood using standard methods. We screened the genes SNCA, PRKN, PINK1 and LRRK2 for sequence variants and, with the exception of $L R R K 2$, for genomic copy number variants. The reference sequence used for the PRKN gene throughout this paper is based on the accession number NM_004562 and codon counting starts from the first ATG.

For SNCA, PRKN and PINK1, all exons were polymerase chain reaction-amplified and sequenced in both directions using BigDye chemistry (Applied Biosystems, Foster City, CA) on an ABI 3100 Genetic Analyzer as previously described $[7,20,21]$. While for the LRRK2 gene, only exon 41 was screened for mutations, using conditions previously described [15].

Gene dosage analysis was performed using the ABI 7900 Sequence Detection System. Exons 1,2, 4-9 and 11-12 of PRKN and exons 1 and 2 of SNCA, as well as the complete coding region of PINK1 were individually co-amplified with $\beta$-globin, which served as an endogenous reference gene. Each plate contained six replicates of every genomic DNA sample, control DNA, and a no-template water control. The cycle in the log phase of PCR amplification at which a significant fluorescence threshold was reached $(C t)$ was used to quantify each exon relative to $\beta$-globin.

\begin{tabular}{|c|c|}
\hline Characteristic & Subjects $(n=66)$ \\
\hline Age at collection (mean $\pm S D$ ) & $60.1 \pm 11.1$ \\
\hline Age at onset (mean $\pm S D)$ & $44.5 \pm 9.3$ \\
\hline Range of age at onset & $20-60$ \\
\hline \multicolumn{2}{|l|}{ Family history } \\
\hline Positive & $39(59.1)$ \\
\hline Negative & $27(40.9)$ \\
\hline
\end{tabular}


The dosage of each exon relative to $\beta$-globin and normalized to control DNA was determined using the 2- $\Delta \Delta C t$ method (Applied Biosystems, Foster City, CA).

\section{Results}

Analysis of both sequence and copy number yielded several parkin mutations in our subset of patients. The positive results found are represented in Table 2, and the electropherograms corresponding to point mutations are shown in Figure 1. We found four patients in whom both alleles were mutated; three of these patients had the same homozygous mutation (c.154delA; p.N52fsX80), a single base pair deletion that inserts a premature stop codon downstream; one patient showed deletion of exon 2 and duplication of exon 5; analysis of a sixth sample (S4) showed data consistent with a homozygous c.1183G > T; p.E395X mutation and a duplication of exon 9; because the co-occurrence of 3 mutations in the same gene is unlikely we designed an additional forward primer that flanked the E395X mutation as close as possible on the 5' side; sequencing of the PCR product generated by amplification with this new primer and primer PRKNexon11R showed the E395X in a heterozygote state, suggesting that the duplication of exon 9 (and presumably exon 10, which we were unable to assay) interfered with the original PCR and sequencing reaction. Thus in Table 2 this mutation is denoted as a compound heterozygous E395X/ exon 9 duplication mutation.

Two samples tested positive for the LRRK2 c.6055G > A; p.G2019S mutation, sample S12 and sample S7. Notably, analysis of sample S7 also showed a heterozygous duplication of PRKN exon 9. Screening of variants E395X, G2019S and 154delA in 252 control chromosomes failed to reveal any control subjects harboring these mutations.
Additionally, we have identified three patients with heterozygous mutations in PRKN: one harboring the T240M variant; another with a deletion of exons 8 through 11 and one with an exon 8 duplication. Furthermore, we have found one patient with two heterozygous dosage variants: an exon 2 deletion and an exon 5 duplication.

No mutations were found in SNCA or PINK1.

\section{Discussion}

We present in this study a detailed mutation analysis of PRKN, PINK1, SNCA and LRRK2. We have included PD patients with a positive family history $(\mathrm{n}=19$ age at onset $<50$ years, $n=20$ age at onset $\geq 50$ years), or early-onset sporadic disease $(n=27)$ in order to maximize our chances of identifying mutations. This approach has led us to find 6 subjects $(9.1 \%)$ with pathogenic mutations in $L R R K 2$ or $P R K N$, in addition to 4 variants of unknown significance in 4 patients.

In our previous report [15] we showed that the c.6055G > A; p.G2019S LRRK2 mutation underlies about $6 \%$ of lateonset PD in the Portuguese population. While we did not find any c.6055G > A; p.G2019S carriers in the 20 lateonset patients studied here, we did identify c.6055G > A; p.G2019S in 2 of 46 early-onset cases. One of these individuals also carried a heterozygous duplication of PRKN exon 9 consistent with the notion of digenic parkinsonism, as previously described [22]. This patient presented no family history consistent with $\mathrm{PD}$, while the other LRRK2 patient had positive family history. Taking into account the removal of samples previously found to carry the c.6055G > A; p.G2019S mutation we calculate that this mutation is present in 9 probands out of the entire series of 132 patients; this represents 2 of 46 early-onset patients, counting only sporadic cases and a single proband from each family (4.3\%) and 7 of 76 late-onset

Table 2: Variants found

\begin{tabular}{|c|c|c|c|c|c|c|c|}
\hline Sample & Gene & Nucleotide change & Amino acid change & Copy variation & Exon & Zygosity & AAO \\
\hline SI & PRKN & 154delA & N52fs $\times 80$ & $\mathrm{~N} / \mathrm{A}$ & 2 & Homo & 30 \\
\hline S2 & PRKN & I54delA & $\mathrm{N} 52 \mathrm{fs} \times 80$ & $N / A$ & 2 & Homo & 35 \\
\hline S3 & $P R K N$ & I54delA & $\mathrm{N} 52 \mathrm{fs} \times 80$ & $N / A$ & 2 & Homo & 21 \\
\hline \multirow[t]{2}{*}{ S4 } & PRKN & GII83T & E395X* & N/A & 11 & Het & 53 \\
\hline & PRKN & N/A & N/A & Duplication & 9 & Het & \\
\hline S5 & $P R K N$ & C719T\# & T240M & N/A & 6 & Het & 55 \\
\hline S6 & $P R K N$ & N/A\# & N/A & Duplication & 8 & Het & 33 \\
\hline \multirow[t]{2}{*}{ S7 } & PRKN & N/A & N/A & Duplication & 9 & Het & 38 \\
\hline & LRRK2 & G6055A & G2019S & N/A & 41 & Het & \\
\hline S8 & $P R K N$ & $\mathrm{~N} / \mathrm{A}^{\#}$ & N/A & Deletion & $8-11$ & Het & 32 \\
\hline \multirow[t]{2}{*}{ SIO } & PRKN & $\mathrm{N} / \mathrm{A}^{\#}$ & $\mathrm{~N} / \mathrm{A}$ & Deletion & 2 & Het & 35 \\
\hline & $P R K N$ & $\mathrm{~N} / \mathrm{A}^{\#}$ & N/A & Duplication & 5 & Het & \\
\hline $\mathrm{S} 12$ & LRRK2 & G6055A & G2019S & N/A & 41 & Het & 41 \\
\hline
\end{tabular}

Homo: Homozygosity; Het: heterozygosity; * previously undescribed mutation; \# Variants of unknown significance e.g pathogenicity not confirmed herein. AAO: Age at onset. 


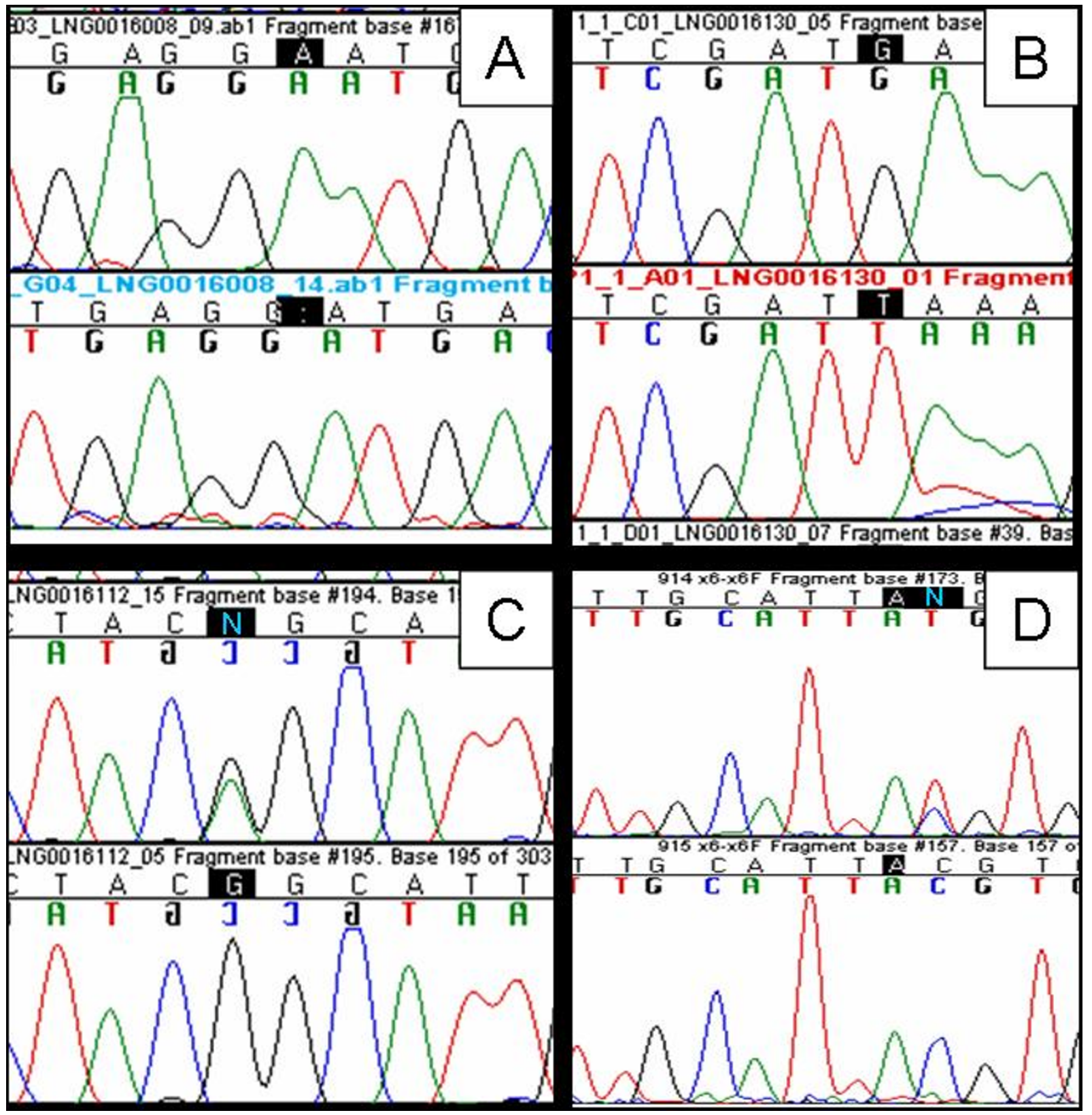

Figure I

Electropherograms of the pathogenic point mutations found. image of the four pathogenic variants discovered in our series. A) chromatogram of the homozygous I54delA in PRKN exon 2, predicted to cause the N52fs X80 aminoacid change; B) chromatogram of the new mutation GI I83T in PRKN exon II, apparently homozygous, predicted to cause a premature stop codon at position 395; C) chromatogram of the heterozygous G6055A in LRRK2 exon 4I, predicted to cause the G20I9S change; D) chromatogram of the heterozygous C7I9T variant in PRKN exon 6, predicted to cause the T240M change.

patients counting only sporadic cases and a single proband from each family (9.2\%).

We found several PRKN mutations as either homozygous or compound heterozygous loss of function changes. The N52fsX80 variant was the most frequent mutation identi- fied in $P R K N$. It was present as a homozygous mutation in three unrelated young onset patients (of 46, 6.5\%). Analysis of relatives of these patients failed to show any heterozygous carriers of this mutation with parkinsonism. We identified a heterozygous deletion of exon 2 and a duplication of exon 5 in PRKN in one early-onset patient with 
positive family history. The only affected family member that was available for testing was the sibling of S10 who presented with the same two variants, albeit with a remarkably different age at onset ( 50 years vs 35 years of patient S10) (Figure 2). While parsimony suggests that these mutations are in trans we were unable to unequivocally establish phase as DNA was unavailable from other family members. We also identified a heterozygous deletion of exons 8 through 11 in a female patient with an age at onset of 32 years. Additional family members were unavailable, so we were unable to determine whether this mutation represented a single contiguous mutation or two mutations existing in trans and thus the pathogenicity of the observed changes remains unknown. We identified a novel mutation in PRKN exon 11 (E395X) as a heterozygous alteration. This patient also possessed a heterozygous duplication of exon 9 . The pathogeneicity of the new E395X mutation is clear since it is a nonsense mutation that occurs upstream of a functional domain of the protein. Of these patients presenting either homozygous or clear compound heterozygous mutations in PRKN, four $(80 \%)$ have an age at onset below 40 years. Only one (patient S4) presents late-onset disease (53 years).

In addition we identified several PRKN variants of unknown significance. The T240M alteration, an exon 8 deletion and an exon 8 duplication were each identified as heterozygous mutations in single patients. In the absence of additional mutations in PRKN in these subjects, we have not considered these as disease causing variants in these patients. We make this statement with caution, since we cannot rule out copy number mutations in exons 3 or 10 , which we were unable to assay effectively.

\section{Conclusion}

It is now clear that genetics plays an important role in the pathogenesis of PD. Specifically, in the Portuguese population, we have found a reasonable number of mutations: the frequency of the c.6055G > A; p.G2019S is one of the highest in Europe, and in the present paper we have found that $8.7 \%$ (4 out of 46 cases) of early-onset cases are attributable to PRKN mutations. Similar to other reports we found PINK1 and SNCA mutations to be a rare cause of disease in our families [23]. Taken as a whole these results have implications mainly for clinicians in Portugal; in particular showing that genetic screening may aid the diagnosis of PD in this population. However, even with the combination of gene dosage and sequencing, a significant proportion of mutations might remain undetected, probably due to the size and the complexity of the PRKN gene. In this way, negative results should be interpreted with caution, as well as heterozygous mutations in this gene.

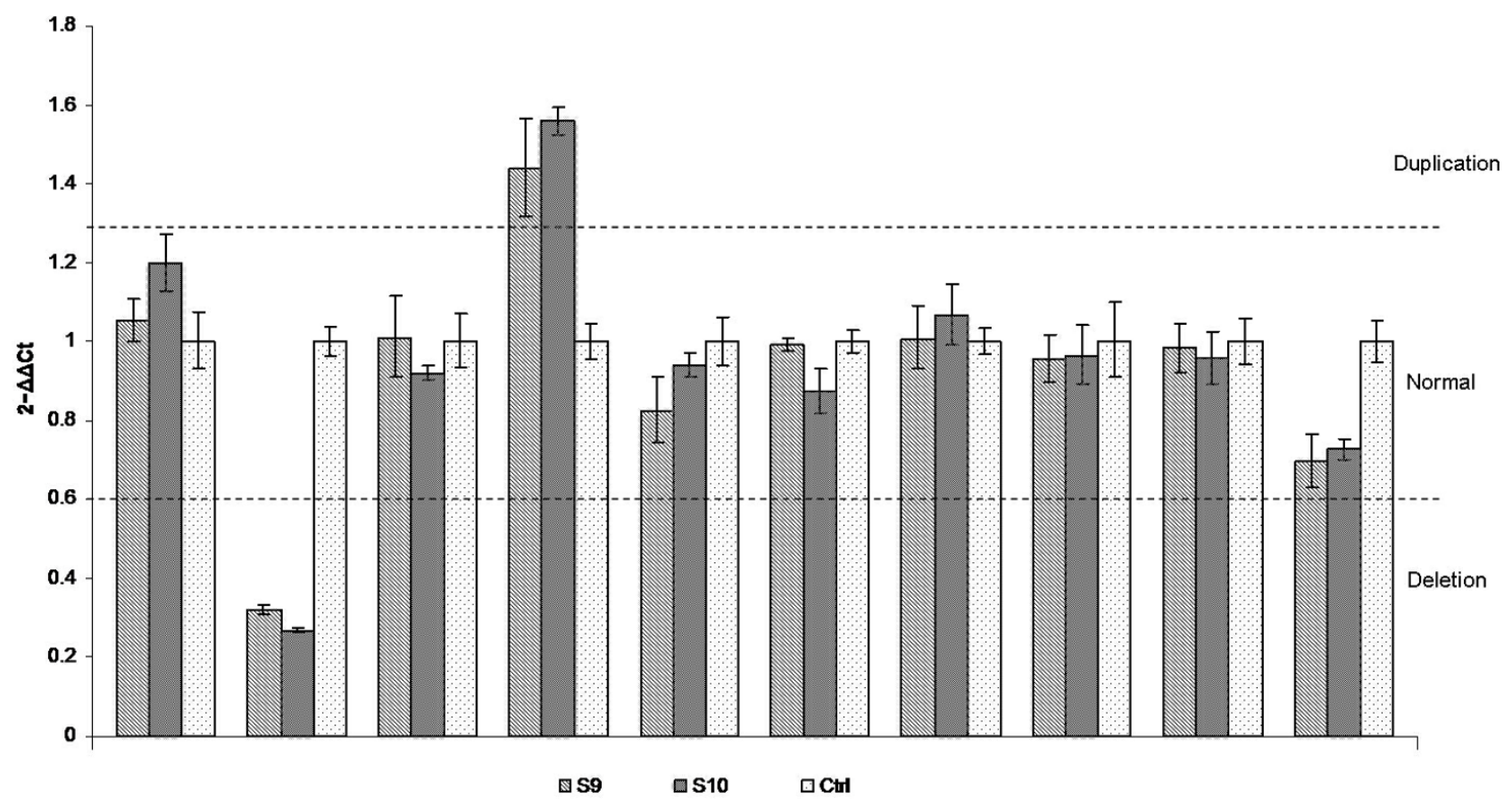

Figure 2

Dosage plots. Dosage plot of the variants found in PRKN in sample SIO and its sibling here denoted as S9. Represented are exons I, 2, 4-9, II and I2. Each exon was compared with the beta-globin gene and normalized to a control DNA. 


\section{Competing interests}

The author(s) declare that they have no competing interests.

\section{Authors' contributions}

$\mathrm{JMB}$ and RJG performed the genotyping, and drafted the manuscript. MHR, CJ, AM, MD, AC and CS contributed to collecting materials. $\mathrm{CRO}, \mathrm{JH}$, and AS participated in the study design and coordination, together with drafting the manuscript. All authors read and approved the final manuscript.

\section{Acknowledgements}

We thank the patients for taking part in this research. This work was supported in part by the Intramural program of the National Institute on Aging, National Institutes of Health, Department of Health and Human Services and FCT grants (SFRH/BD/29647/2006) and (SFRH/BD/27442/2006).

\section{References}

I. Dauer W, Przedborski S: Parkinson's disease: mechanisms and models. Neuron 2003, 39(6):889-909.

2. Hughes AJ, Daniel SE, Kilford L, Lees AJ: Accuracy of the clinical diagnosis of idiopathic Parkinson's disease: A clinicapathological study of 100 cases. J Neurol Neurosurg Psychiatry 1992, 55:181-184.

3. Gwinn-Hardy K: Genetics of parkinsonism. Mov Disord 2002, I 7(4):645-656.

4. Valente EM, Abou-Sleiman PM, Caputo V, Muqit MM, Harvey K, Gispert S, Ali Z, Del Turco D, Bentivoglio AR, Healy DG, Albanese A, Nussbaum R, Gonzalez-Maldonado R, Deller T, Salvi S, Cortelli P, Gilks WP, Latchman DS, Harvey RJ, Dallapiccola B, Auburger G, Wood NW: Hereditary early-onset Parkinson's disease caused by mutations in PINKI. Science 2004, 304(5674): II58-II60.

5. Bonifati V, Breedveld GJ, Squitieri F, Vanacore N, Brustenghi $P$, Harhangi BS, Montagna P, Cannella M, Fabbrini G, Rizzu P, van Duijn CM, Oostra BA, Meco G, Heutink P: Localization of autosomal recessive early-onset parkinsonism to chromosome Ip36 (PARK7) in an independent dataset. Ann Neurol 2002, S I(2):253-256.

6. Polymeropoulos MH, Lavedan C, Leroy E, Ide SE, Dehejia A, Dutra A, Pike B, Root H, Rubenstein J, Boyer R, Stenroos ES, Chandrasekharappa S, Athanassiadou A, Papapetropoulos T, Johnson WG, Lazzarini AM, Duvoisin RC, Di lorio G, Golbe LI, Nussbaum RL: Mutation in the alpha-synuclein gene identified in families with Parkinson's disease. Science 1997, 276(532 I):2045-2047.

7. Kitada T, Asakawa S, Hattori N, Matsumine $H$, Yamamura $Y$, Minoshima S, Yokochi M, Mizuno Y, Shimizu N: Mutations in the parkin gene cause autossomal recessive juvenile parkinsonism. Nature 1998, 392:605-608.

8. Paisan-Ruiz C, Jain S, Evans EW, Gilks WP, Simon J, van der Brug M, Lopez de Munain A, Aparicio S, Gil AM, Khan N, Johnson J, Martinez JR, Nicholl D, Carrera IM, Pena AS, de Silva R, Lees A, Marti-Masso JF, Perez-Tur J, Wood NW, Singleton AB: Cloning of the gene containing mutations that cause PARK8-linked Parkinson's disease. Neuron 2004, 44(4):595-600.

9. Zimprich A, Biskup S, Leitner P, Lichtner P, Farrer M, Lincoln S, Kachergus J, Hulihan M, Uitti RJ, Calne DB, Stoessl AJ, Pfeiffer RF, Patenge N, Carbajal IC, Vieregge P, Asmus F, Muller-Myhsok B, Dickson DW, Meitinger T, Strom TM, Wszolek ZK, Gasser T: Mutations in LRRK2 cause autosomal-dominant parkinsonism with pleomorphic pathology. Neuron 2004, 44(4):60I-607.

10. Singleton AB, Farrer M, Johnson J, Singleton A, Hague S, Kachergus J, Hulihan M, Peuralinna T, Dutra A, Nussbaum R, Lincoln S, Crawley A, Hanson M, Maraganore D, Adler C, Cookson MR, Muenter M, Baptista M, Miller D, Blancato J, Hardy J, Gwinn-Hardy K: alphaSynuclein locus triplication causes Parkinson's disease. Science 2003, 302(5646):84I.

II. Hedrich K, Djarmati A, Schafer N, Hering R, Wellenbrock C, Weiss $\mathrm{PH}$, Hilker R, Vieregge P, Ozelius LJ, Heutink P, Bonifati V, Schwinger
E, Lang AE, Noth J, Bressman SB, Pramstaller PP, Riess O, Klein C: DJI (PARK7) mutations are less frequent than Parkin (PARK2) mutations in early-onset Parkinson disease. Neurology 2004, 62:389-394.

12. Abou-Sleiman PM, Healy DG, Quinn N, Lees AJ, Wood NW: The role of pathogenic DJ-I mutations in Parkinson's disease. Ann Neurol 2003, 54(3):283-286.

13. Bonifati V, Rizzu P, van Baren MJ, Schaap O, Breedveld GJ, Krieger E, Dekker MC, Squitieri F, Ibanez P, Joosse M, van Dongen JW, Vanacore N, van Swieten JC, Brice A, Meco G, van Duijn CM, Oostra BA, Heutink P: Mutations in the DJ-I gene associated with autosomal recessive early-onset parkinsonism. Science 2003, 299(5604):256-259.

14. Hering R, Strauss KM, Tao X, Bauer A, Woitalla D, Mietz EM, Petrovic S, Bauer P, Schaible W, Muller T, Schols L, Klein C, Berg D, Meyer PT, Schulz JB, Wollnik B, Tong L, Kruger R, Riess O: Novel homozygous p.E64D mutation in DJI in early onset Parkinson disease (PARK7). Hum Mutat 2004, 24(4):32I-329.

15. Bras JM, Guerreiro RJ, Ribeiro MH, Januário C, Morgadinho AS, Oliveira C, Cunha L, Hardy J, Singleton A: G20I9S Dardarin Substitution is a Common Cause of Parkinson's Disease in a Portuguese Cohort. Mov Disord 2005, 20( I 2): I653-I655.

16. Brice A: Genetics of Parkinson's disease: LRRK2 on the rise. Brain 2005, I 28(Pt I 2):2760-2762.

17. Lesage S, Durr A, Tazir M, Lohmann E, Leutenegger AL, Janin S, Pollak P, Brice A: LRRK2 G20 I 9S as a cause of Parkinson's disease in North African Arabs. N Engl J Med 2006, 354(4):422-423.

18. Ozelius LJ, Senthil G, Saunders-Pullman R, Ohmann E, Deligtisch A, Tagliati M, Hunt AL, Klein C, Henick B, Hailpern SM, Lipton RB, SotoValencia J, Risch N, Bressman SB: LRRK2 G20I9S as a cause of Parkinson's disease in Ashkenazi Jews. N Engl J Med 2006, 354(4):424-425.

19. Gelb DJ, Oliver E, Gilman S: Diagnostic criteria for Parkinson disease. Arch Neurol 1999, 56:33-39.

20. Berg D, Niwar M, Maass S, Zimprich A, Moller JC, Wuellner U, Schmitz-Hubsch T, Klein C, Tan EK, Schols L, Marsh L, Dawson TM, Janetzky B, Muller T, Woitalla D, Kostic V, Pramstaller PP, Oertel WH, Bauer P, Krueger R, Gasser T, Riess O: Alpha-synuclein and Parkinson's disease: implications from the screening of more than I,900 patients. Mov Disord 2005, 20(9): I I9I-I 194.

21. Hatano Y, Li Y, Sato K, Asakawa S, Yamamura Y, Tomiyama H, Yoshino H, Asahina M, Kobayashi S, Hassin-Baer S, Lu CS, Ng AR, Rosales RL, Shimizu N, Toda T, Mizuno Y, Hattori N: Novel PINK I mutations in early-onset parkinsonism. Ann Neurol 2004, 56(3):424-427.

22. Dachsel JC, Mata IF, Ross OA, Taylor JP, Lincoln SJ, Hinkle KM, Huerta C, Ribacoba R, Blazquez M, Alvarez V, Farrer MJ: Digenic parkinsonism: investigation of the synergistic effects of PRKN and LRRK2. Neurosci Lett 2006, 4I 0(2):80-84.

23. Wood-Kaczmar A, Gandhi S, Wood NW: Understanding the molecular causes of Parkinson's disease. Trends Mol Med 2006, I 2(I I):52I-528.

\section{Pre-publication history}

The pre-publication history for this paper can be accessed here:

\section{http://www.biomedcentral.com/1471-2377/8/1/prepub}

